\title{
Intrathoracic negative pressure therapy and/or endobronchial valve for pleural empyema minimal invasive management: case series of thirteen patients and review of the literature
} \author{
Aliaksandr Ihnatsiuk ${ }^{2}$ \\ ${ }^{1}$ Faculty of Health Sciences, Jan Kochanowski University of Humanities and Sciences, Kielce, Poland \\ ${ }^{2}$ Department of Thoracic Surgery, Brest Regional Hospital, Brest, Belarus \\ ${ }^{3}$ Department of Anatomy and Physiology, Brest State University, Brest, Belarus
}

Siarhei Panko모 Denis Vakulich², Aliaksandr Karpitski², Henadzi Zhurbenka², Andrej Shestiuk ${ }^{3}$, Rostislav Boufalik²,

Videosurgery Miniinv 2020; 15 (4): 588-595 DOI: https://doi.org/10.5114/wiitm.2020.93210

\begin{abstract}
Introduction: Intrathoracic negative pressure therapy is an adjunct to standard methods of complex empyema management in debilitated patients. Nevertheless, the use of endoscopic one-way endobronchial valves to successfully close large bronchopleural fistulas in patients with advanced pleural empyema has been described in only a few case reports.

Aim: To present our experience in managing complex pleural empyema using thoracostomy with intrathoracic negative pressure therapy and/or endobronchial valve implantation.

Material and methods: We retrospectively analyzed data from 13 consecutive patients (11 men, mean age: 56 years, range: 38-80 years) who were treated for pleural empyema using thoracostomy with intrathoracic negative pressure therapy and/or endobronchial valve implantation between October 2015 and November 2017.

Results: The control of empyema was satisfactory in 12 patients; however, 1 patient died from sepsis-related multiorgan failure despite complete cessation of air leak on day 9 after endobronchial valve implantation. The overall success rate for the final closure of the chest wall was 9/12 patients (75\%): in 5 patients, the wall closed spontaneously, and in 4, the wall was closed using thoracomyoplasty.

Conclusions: Thoracostomy with intrathoracic negative pressure therapy, endobronchial valve implantation with tube drainage, and a combination of the two could adequately manage patients with pleural empyema with or without a persistent air leakage fistula.
\end{abstract}

Key words: bronchopleural fistula, video-assisted thoracoscopic surgery, empyema, intrathoracic negative pressure therapy, endobronchial valve.

\section{Introduction}

Since the first report [1] of intrapleural vacuum-assisted closure (VAC) therapy in 2006, many investigators have demonstrated the advantages and effectiveness of intrathoracic negative pressure therapy (INPT) in patients with complex empyema of various etiologies with or without bronchopleural fistulas (BPFs). The current European Association for Cardio-Thoracic Surgery expert consensus statement [2] and the American Association for Thoracic Surgery guidelines for pleural empyema manage- 
ment [3] have established the role of intrathoracic VAC therapy as an adjunct to standard surgical treatment methods for the management of complicated empyema with or without BPFs, especially in debilitated patients. Nevertheless, the use of one-way endobronchial valves (EBVs) for the successful closure of peripheral large air leaks in patients with advanced pleural empyema has been limited to a few case reports and small series [4].

\section{Aim}

We aimed to present our experience in managing complex pleural empyema using thoracostomy with intrathoracic negative pressure therapy and/or endobronchial valve implantation.

\section{Material and methods}

We retrospectively reviewed data from 13 consecutive patients (11 men) with a mean age of 56 years (range: $38-80$ years) who were treated for pleural empyema using open, mini-, or tube-thoracostomy with INPT and/or with EBV implantation between October 2015 and November 2017; this sample constitutes all patients seen at our hospital for this condition with this intervention. This study was approved by our institutional ethics committee, and written informed consent from the patients was waived as this is a retrospective study, and these consents had been obtained from each patient before any surgery/invasive procedures were performed. Demographic and clinical characteristics of patients prior to the onset of the aforementioned treatments are summarized in Table I.

The majority of patients had stage III empyema $(n=9)$, central or peripheral BPFs $(n=11)$, and poor general condition with Karnofsky index $\leq 50 \%$ $(n=7)$, which made them unsuitable for major thoracic surgery. Eight (62\%) patients had primary, $3(23 \%)$ had secondary, and $2(15 \%)$ had recurrent etiologies of pleural empyema.

EBVs were made from rubber composite material (MedLung, Barnaul, Russian Federation) [5]. Implantation was performed either under general anesthesia with a flexible bronchoscope inserted through an endotracheal tube during surgery or under moderate sedation if valve implantation or correction of its malposition was done pre- or postoperatively.

The airway leading to the air leak was identified by instillation of $1 \%$ Viride nitens (brilliant green) solution diluted (1 : 30$)$ with $3 \%$ hydrogen peroxide via the chest tube. After the visual assessment of the dyed bronchus diameter with endobronchial forceps of various sizes, EBV of diameter larger by 2-3-mm of the bronchial diameter was advanced into the affected airway (Photo 1) while a marked decrease in air leak via the chest tube into the water seal chamber was achieved.

\section{Operative technique}

We performed open or video-assisted (VATS) thoracic surgical procedures consisting of pus evacuation, debridement, local decortication, and BPF closure with direct interrupted sutures when applicable, as well as flushing of the cavity with saline through open window thoracostomy (OWT) after partial resection $(5 \mathrm{~cm})$ of two ribs or via the retracted orifice after closed tube thoracostomy.

The pleural cavity was loosely filled with povidone iodine-soaked gauze(s), which had been wrapped around a chest tube with lateral perforations, and closed with an adhesive film attached over the skin margins of the thoracostomy. Wall suction was set to apply intrathoracic negative pressure ranging from -75 to $-150 \mathrm{~mm} \mathrm{Hg}$ through the chest tube, previously placed using an additional intercostal aperture or via the film. In clinically stable patients, the suction was alternated with water seal for $1 \mathrm{~h}$ but not for more than five times a day. Wound revisions and dressing changes were performed two-three times a week under moderate sedation. After inpatient culture-specific systemic antimicrobial therapy, patients with unclosed OWT/ wounds were treated with conventional wound care in outpatient settings.

\section{Results}

Treatment modalities with INPT and EBV implantation as well as their outcomes are shown in Table II.

The control of empyema and sepsis was satisfactory in 12 patients; however, 1 patient who was treated with EBV and drainage of the chest died of sepsis-related multiorgan failure, despite complete cessation of the air leak on day 9 after EBV implantation. The median postoperative length of hospital stay for all patients, excluding the deceased patient, was 21 days (range: 13-182 days). BPF closure was achieved in all surviving patients, and the median time from the beginning of the therapy to air leak 
Table I. Demographics of patients and empyema pathogenesis

\begin{tabular}{|c|c|c|c|c|c|}
\hline $\begin{array}{l}\text { Variable/ } \\
\text { patient }\end{array}$ & $\begin{array}{l}\text { Sex/ } \\
\text { age }\end{array}$ & $\mathrm{KI}$ & $\begin{array}{l}\text { Underlying disease/ } \\
\text { pathogenesis/treatment }\end{array}$ & $\begin{array}{l}\text { Empyema onset } \\
\text { days/stage }\end{array}$ & $\begin{array}{l}\text { Preoperative microbiology } \\
\text { of pleural fluid }\end{array}$ \\
\hline P1 & $M / 60$ & $50 \%$ & CANP, CT & $\begin{array}{c}>3000 \\
\text { III }\end{array}$ & Staphylococcus aureus \\
\hline P2 & $M / 48$ & $70 \%$ & $\begin{array}{l}\text { SCLC, pneumonectomy, ChT, } \\
\text { cancer recurrence, tracheopleural } \\
\text { fistula } 5 \mathrm{~mm} \text {, chest wall phleg- } \\
\text { mon drainage, } \mathrm{CT}+\mathrm{Al}\end{array}$ & $\begin{array}{l}80 \\
111\end{array}$ & Sterile cultures \\
\hline P3 & $M / 62$ & $70 \%$ & $\begin{array}{c}\text { CANP, CT, peripheral BPF, VATS } \\
\text { DBR, CT }+ \text { Al }\end{array}$ & $\begin{array}{l}82 \\
111\end{array}$ & Sterile cultures \\
\hline P4 & $M / 48$ & $50 \%$ & $\begin{array}{l}\text { CANP, lower and middle lobe gan- } \\
\text { grene, } C T+\mathrm{Al} \text {, peripheral BPF }\end{array}$ & $\begin{array}{l}65 \\
\text { III }\end{array}$ & Pseudomonas aeruginosa \\
\hline P5 & $F / 69$ & $<50 \%$ & $\begin{array}{l}\text { Bullous disease, PTX, CT, periph- } \\
\text { eral BPF, repeat PE, sepsis }\end{array}$ & $\begin{array}{l}44 \\
\text { III }\end{array}$ & $\begin{array}{c}\text { Pseudomonas aeruginosa/Proteus } \\
\text { mirabilis/Klebsiella pneumonia/ } \\
\text { Acinetobacter baumannii/Proteus } \\
\text { vulgaris }\end{array}$ \\
\hline P6 & $M / 80$ & $<50 \%$ & COPD, PTX, CT, peripheral BPF & $\begin{array}{c}198 \\
\text { III }\end{array}$ & $\begin{array}{c}\text { Pseudomonas aeruginosa/Klebsiella } \\
\text { pneumonia }\end{array}$ \\
\hline P7 & $M / 48$ & $<50 \%$ & $\begin{array}{c}\text { CANP, right lung gangrene, } \\
\text { pneumonectomy, CT }+ \text { Al, central } \\
\text { BPF } 2 \mathrm{~mm}\end{array}$ & $\begin{array}{l}52 \\
\text { III }\end{array}$ & Klebsiella pneumonia \\
\hline P8 & $M / 39$ & $50 \%$ & CANP, CT, peripheral BPF & $\begin{array}{l}42 \\
\text { III }\end{array}$ & $\begin{array}{l}\text { Staphylococcus epidermidis/Proteus } \\
\text { mirabilis/Pseudomonas aeruginosa }\end{array}$ \\
\hline P9 & $M / 59$ & $<50 \%$ & $\begin{array}{c}\text { Bronchiectasis, PTX, CT, periph- } \\
\text { eral BPF }\end{array}$ & $\begin{array}{l}6 \\
1\end{array}$ & Staphylococcus epidermidis \\
\hline P10 & $M / 54$ & $70 \%$ & $\begin{array}{l}\text { CANP, lobar abscess, } \mathrm{CT}+\mathrm{Al} \text {, } \\
\text { peripheral BPF }\end{array}$ & $\begin{array}{c}29 \\
11\end{array}$ & Sterile cultures \\
\hline P11 & $M / 52$ & $70 \%$ & $\begin{array}{l}\text { Chest injury, hemothorax, CT, } \\
\text { peripheral BPF }\end{array}$ & $\begin{array}{c}24 \\
11\end{array}$ & $\begin{array}{c}\text { Candida albicans/Pseudomonas } \\
\text { aeruginosa }\end{array}$ \\
\hline P12 & $F / 57$ & $50 \%$ & $\begin{array}{c}\text { CANP, aspiration, lobar abscess, } \\
\text { CT, peripheral BPF }\end{array}$ & $\begin{array}{l}37 \\
\|-|I|\end{array}$ & Pseudomonas aeruginosa \\
\hline P13 & $M / 50$ & $50 \%$ & CANP, CT & $\begin{array}{l}54 \\
\text { III }\end{array}$ & Serratia species \\
\hline
\end{tabular}

$P$ - patient, Al - antiseptic irrigation, BPF - bronchopleural fistula, CANP - community-acquired necrotizing pneumonia, COPD - chronic obstructive pulmonary disease, ChT - chemotherapy, CT - chest tube, DBR - debridement, EBV - endobronchial one-way valve, INPT - intrathoracic negative pressure therapy, KI - Karnofsky index, PE - pulmonary embolism, PTX - pneumothorax, SCLC - small cell lung cancer, VATS - video-assisted thoracic surgery.

resolution without thoracoplasty was 15 (7-21) days for the eight surviving patients. Moreover, in 2 patients treated with thoracostomy-INPT and EBV implantation (Photo 2) (P10, P11) and in 1 patient with a large peripheral BPF treated with thoracostomy-INPT alone (P12), the pulmonary parenchyma re-expanded and the thoracic wall was closed spontaneously without thoracoplasty.

The overall success rate for the final closure of the chest wall was 9/12 patients (75\%): in 5 patients, the wall closed spontaneously over a median of 29 days (range: 14-250 days), and in 4 patients with thoracomyoplasty, the wall closed at a mean of
229 days (range: 111-540 days) from the start of treatment with INPT and/or EBV implantation. None of the patients presented evidence of chronic/recurrent empyema at the 3-month outpatient follow-up after chest wall closure. One patient (P2) was not scheduled for wall closure because of cancer recurrence. One patient (P3) refused closure of the OWT, and another 80-year-old patient (P6) rejected thoracostomy-INPT, thereby choosing to live with a permanent thoracic wall defect/wound, chronic mild-symptom empyema, and EBV left in place; nevertheless, there was no air leakage at a 7-month post-discharge follow-up. 


\section{Discussion}

It is well known that the surgical management of pleural empyema is a long-term and multi-step treatment and is successful provided that the bronchopleural fistula is reliably closed in a short period of time, especially with a minimally invasive approach, which significantly reduces perioperative stress and allows faster recovery after surgery [6].

In this study, a septic process was satisfactorily controlled in 12/13 (92\%) patients with pleural empyema using thoracostomy with INPT and/or EBV implantation; however, 1 patient died from sepsis-related multiorgan failure despite complete cessation of air leak after endobronchial valve implantation without INPT. The treatment experience of complex pleural empyema shown in this study encouraged us to develop an empyema treatment concept based on a combination of endobronchial implantation of unilateral valves and negative pressure wound therapy for the complete evacuation of pus and maximum re-expansion of the lung parenchyma. We could not find any reports in the current literature describing this combination of simultaneous use of endobronchial one-way valves and thoracostomy (open and miniVATS) with vacuum-assisted closure/intrathoracic negative pressure therapy for the spontaneous closure of the chest wall of patients with parapneumonic (patient 10) and posttraumatic (patient 11) pleural empyema with peripheral bronchopleural fistulas or large air leaks.

In 2006, Varker and $\mathrm{Ng}$ [1] presented the first successful case of complete healing and closure of a post-lobectomy empyema without BPF using a VAC device and recommended that the VAC device be tried for post-resectional empyema with or without previously closed BPFs.

Accelerated treatment of postpneumonectomy empyema developed by Schneiter et al. [7] consisted of repeated open surgical debridement of the pleural cavity and negative pressure wound therapy of the temporary closed chest cavity filled with povidone-iodine-soaked towels after closure and reinforcement of BPF, if present. This procedure resulted in $94.6 \%$ definitive closure of the cavity with an antibiotic solution within 8 days.

Palmen et al. [8] showed that VAC treatment of recurrent empyema in the presence of the residual lung tissue with or without alveolopleural fistula achieved spontaneous OWT closure through the acceleration of tissue granulation. There was such

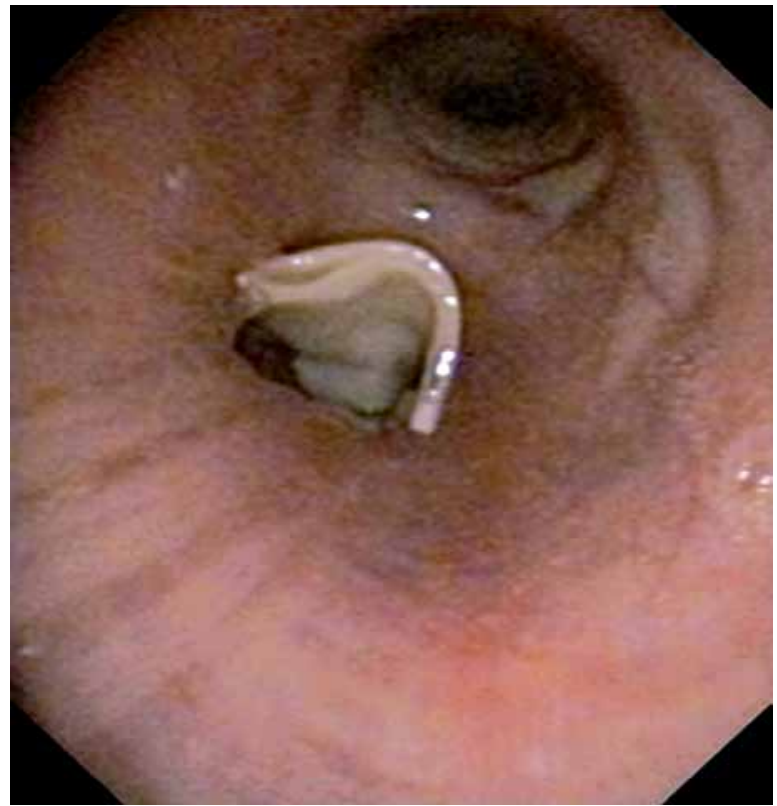

Photo 1. Proximal part with the falling petal valve of the rubber endobronchial prosthesis is seen, while its distal cylindrical part is implanted in the affected upper segment of the left lower lobe (patient 10)

significant improvement of the residual pulmonary parenchyma expansion that two debilitated patients were weaned from ventilator support because of pulmonary function improvements.

In 2011, Sziklavari et al. [9] described 2 cases of acute empyema with BPF treated using re-thoracotomy and pneumectomy/debridement with subsequent closure of dehisced bronchial stumps with direct stitches, a pericardial flap, and OWT-VAC therapy. Successful spontaneous closure was achieved in the case of the smaller recurrent BPF $(1 \mathrm{~mm})$; however, the larger one $(8 \mathrm{~mm})$ remained open, and the patient died of sepsis-related multiorgan failure despite the fact that his thoracic cavity was sterile during VAC therapy.

The same group formulated the very important postulate that acute sepsis, failed primary surgical intervention, or its complications are indications for OWT and VAC intervention, and the presence of small BPFs and residual lung tissue is not a contraindication for VAC therapy. These authors also developed a minimally invasive VAC therapy without classic OWT [10,11] and presented the short- and long-term outcomes of three VAC techniques: OWTVAC, minimally invasive technique (Mini-VAC), and 
Table II. Treatment modalities and outcomes

\begin{tabular}{|c|c|c|c|c|c|c|c|}
\hline $\begin{array}{l}\text { Variable/ } \\
\text { patient }\end{array}$ & $\begin{array}{l}\text { Treatment } \\
\text { modality }\end{array}$ & $\begin{array}{c}\text { AIR } \\
\text { [days] }\end{array}$ & $\begin{array}{l}\text { INPT days/ } \\
\text { changes }\end{array}$ & $\begin{array}{l}\text { Antibiotic } \\
\text { therapy } \\
\text { [days] }\end{array}$ & $\begin{array}{l}\text { Postoperative } \\
\text { hospital stay } \\
\text { [days] }\end{array}$ & $\begin{array}{c}\text { Outcome of INPT } \\
\text { and/or EBV }\end{array}$ & $\begin{array}{c}\text { Chest wall closed } \\
\text { (post-discharge } \\
\text { day) }\end{array}$ \\
\hline P1 & OWT/DBR/INPT & N/A & $15 / 4$ & 16 & 28 & $\begin{array}{c}\mathrm{KI}>70 \% \text {, } \\
\text { OWT/chronic, } \\
\text { Empyema }\end{array}$ & $\begin{array}{c}\text { Yes } \\
\text { Thoracoplasty (140) }\end{array}$ \\
\hline P2 & $\begin{array}{l}\text { OWT/DBR/BPF } \\
\text { suturing/INPT }\end{array}$ & 16 & $23 / 6$ & 11 & 25 & $\begin{array}{c}\text { Empyema \& BPF } \\
\text { healed/OWT }\end{array}$ & No \\
\hline P3 & OWT/DBR/INPT & 21 & $11 / 3$ & 21 & 24 & $\begin{array}{c}\text { Empyema \& BPF } \\
\text { healed/OWT }\end{array}$ & No \\
\hline P4 & OWT/DBR/INPT & No & $13 / 5$ & 13 & 14 & $\begin{array}{c}\mathrm{KI}>70 \%, \mathrm{BPF} / \\
\text { OWT/chronic } \\
\text { Empyema }\end{array}$ & $\begin{array}{c}\text { Yes } \\
\text { Thoracoplasty } \\
540\end{array}$ \\
\hline P5 & $\begin{array}{c}12 \mathrm{~mm} \varnothing \mathrm{EBV} \text { into } \\
\mathrm{LLL} / \mathrm{CT} / \mathrm{MV}\end{array}$ & 9 & N/A & 18 & 18 & $\begin{array}{l}\text { Death due to } \\
\text { sepsis }\end{array}$ & N/A \\
\hline P6 & $\begin{array}{c}12 \mathrm{~mm} \varnothing \text { EBV } \\
\text { into } \mathrm{RLL} / \mathrm{CT} / \mathrm{MV}= \\
51 \text { days }\end{array}$ & 20 & N/A & 176 & 182 & $\begin{array}{c}\text { KI 70\%, BPF } \\
\text { healed/chronic } \\
\text { Empyema/EBV/ } \\
\text { CT }\end{array}$ & No \\
\hline P7 & $\begin{array}{l}\text { OWT/DBR/BPF } \\
\text { suturing/INPT }\end{array}$ & 19 & $18 / 5$ & 20 & 20 & $\begin{array}{c}\mathrm{KI}>70 \%, \\
\text { Empyema \& BPF } \\
\text { healed/OWT }\end{array}$ & $\begin{array}{c}\text { Yes } \\
\text { Thoracoplasty } \\
(111)\end{array}$ \\
\hline P8 & OWT/DBR/INPT & No & $17 / 4$ & 12 & 13 & $\begin{array}{l}\mathrm{KI}>70 \% \\
\text { BPF/OWT }\end{array}$ & $\begin{array}{c}\text { Yes } \\
\text { Thoracoplasty } \\
(126)\end{array}$ \\
\hline P9 & $\begin{array}{c}12 \mathrm{~mm} \varnothing \mathrm{EBV} \text { into } \\
\mathrm{RBI} / \mathrm{CT}\end{array}$ & 8 & N/A & 13 & 14 & $\begin{array}{c}\mathrm{KI}>70 \%, \\
\text { Empyema \& BPF } \\
\text { healed }\end{array}$ & $\begin{array}{c}\text { Yes } \\
\text { Spontaneously } \\
(0)\end{array}$ \\
\hline P10 & $\begin{array}{c}\text { (1) } 10 \mathrm{~mm} \varnothing \text { EBV } \\
\text { into LLL-B6/CT } \\
\text { (2) OWT/DBR/ } \\
12 \mathrm{~mm} \varnothing \mathrm{EBV} \text { into } \\
\text { LLL/INPT }\end{array}$ & $\begin{array}{l}\text { No } \\
7\end{array}$ & $19 / 4$ & 13 & 29 & $\begin{array}{c}\text { Empyema \& BPF } \\
\text { healed/OWT/ } \\
\text { EBV }^{*}\end{array}$ & $\begin{array}{c}\text { Yes } \\
\text { Spontaneously } \\
(29)\end{array}$ \\
\hline P11 & $\begin{array}{c}\text { VATS-DBR/11 mm } \\
\varnothing \text { EBV into RLL/ } \\
\text { INPT }\end{array}$ & 12 & $17 / 4$ & 7 & 20 & $\begin{array}{c}\text { Empyema \& BPF } \\
\text { healed/EBV }{ }^{\star \star}\end{array}$ & $\begin{array}{c}\text { Yes } \\
\text { Spontaneously } \\
(27)\end{array}$ \\
\hline P12 & OWT/DBR/INPT & 14 & $15 / 4$ & 9 & 18 & $\begin{array}{c}\mathrm{KI}>70 \% \\
\text { Empyema \& BPF } \\
\text { healed/OWT }\end{array}$ & $\begin{array}{c}\text { Yes } \\
\text { Spontaneously (48) }\end{array}$ \\
\hline P13 & OWT/DBR/INPT & N/A & $20 / 5$ & 21 & 22 & $\begin{array}{l}\text { KI 70\%, chronic } \\
\text { Empyema/OWT }\end{array}$ & $\begin{array}{c}\text { Yes } \\
\text { Spontaneously } \\
(250)\end{array}$ \\
\hline
\end{tabular}

$P$ - patient, $A I R$ - air leak resolution, BPF-bronchopleural fistula, $C T$ - chest tube, DBR-debridement, EBV-endobronchial one-way valve, INPT - intrathoracic negative pressure therapy, LLL - left lower lobe, KI-Karnofsky index, MV-mechanical ventilation, OWT-open window thoracostomy, LLL-B6 - superior segment of left lower lobe, RBI-right bronchus intermedius, $R L L$-right lower lobe, VATS-video-assisted thoracic surgery, N/A - not applicable. ${ }^{\star} E B V$ removed on post-discharge day $20,{ }^{\star *} E B V$ removed on post-discharge day 29.

instillation (Mini-VAC-Instill) [12]. They concluded that the advantage of both minimally invasive modalities was the high rate of chest wall closure within the same hospital stay $(60 \%, 100 \%$, and $87 \%$ respectively) and that BPF is not a contraindication for
VAC. Finally, they concluded that a large BPF could be closed using a muscle or pericardium flap after OWT-VAC therapy.

Taken together, these data suggest that INPT is a safe and efficient adjunct to standard open or min- 

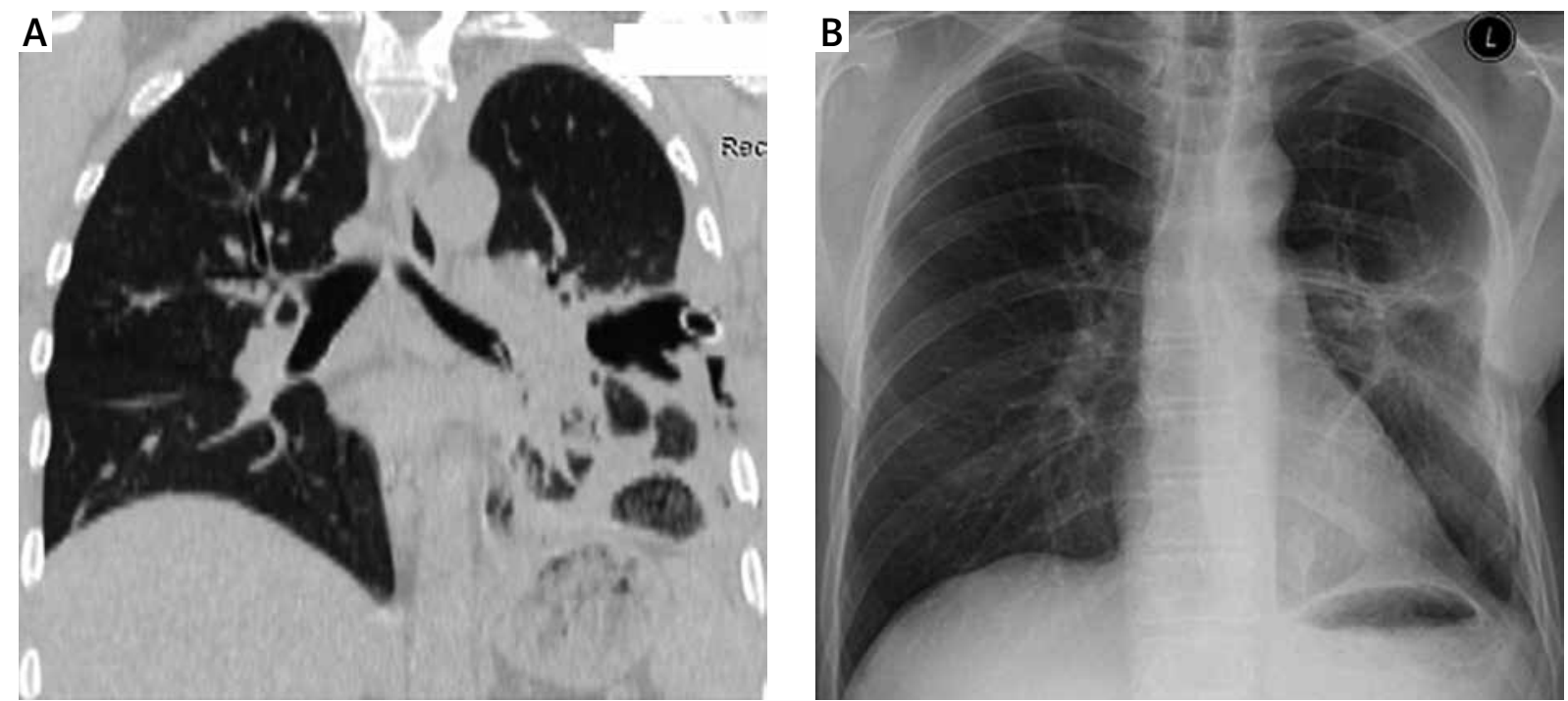

Photo 2. A - Computed tomography showing parapneumonic pleural empyema with atelectasis of the left lower lobe after endobronchial valve implantation into the segmental bronchus (B6) and chest tubes drainage (Patient 10). B - Chest radiography of this patient on day 29 post-discharge showing re-expansion of the lung after treatment by replacement of endobronchial valve in the left lower lobe and thoracostomy with intrathoracic negative pressure therapy

imally invasive/VATS surgery for the management of complex pleural empyema because it potentially reduces OWT-related mortality and morbidity and helps to avoid an OWT. It can be used as a bridge [13] for reconstructive surgery or for definitive closure of the empyema cavity depending on the etiology, general condition of the patient, and current stage of disease [14], especially if large BPFs have been previously closed.

The gold standard for the treatment of BPFs remains surgery; however, treatment with EBV implantation should be considered the first-line approach in high-risk patients or in cases where the surgical option has failed [15].

In 2005, Snell et al. [16] presented the first description of noninvasive successful treatment of a patient with a bronchocutaneous fistula persisting for 6 years following right upper lobotomy and thoracoplasty for aspergillomas using EBV unidirectional prosthesis, originally developed for the treatment of severe emphysema.

Subsequently, Schweigert et al. [17] described the successful treatment of 2 patients with parapneumonic empyema using EBV implantation to block the segmental bronchus leading to a persisting peripheral BPF, occurring in both patients after minimally invasive VATS with pleural debridement.
In 2013, Gudbjartsson et al. [18] reported the successful implantation of EBVs into the B1 and B2 segmental bronchi for the treatment of a patient with BPF persisting for 6 months after surgical treatment of necrotizing pneumonia. Mahajan et al. [19] described the successful use of EBV in the treatment of postpneumonectomy empyema with BPF in patients requiring mechanical ventilation. Kalatoudis et al. [20] reported a case where EBV implantation facilitated endotracheal extubation of a patient with a parapneumonic empyema, BPF, acute respiratory distress syndrome, and severe respiratory failure on prolonged mechanical ventilation. In general, very few cases of successful use of EBV with chest drainage in patients with empyema and BPF have been described, perhaps because this method is used only in empyema patients with a poor condition and very high surgical risk who are not suitable for primary major chest surgery or reoperation.

Two types of EBVs, the Zephyr EBV (Pulmonx, Redwood City, CA) and Spiration IBV (Olympus Respiratory America, Redmond, WA), are currently available in Europe and the United States [4], and one is available in the Russian Federation (MedLung, Barnaul, $\mathrm{RU})$. Levin et al. [5] published the results of minimally invasive treatment of patients with destructive pulmonary multidrug-resistant tuberculosis and showed 
that EBV implantation led to faster bacteriological conversion, cavity closure, and reversible changes in the respiratory function, whereas the majority of patients (55\%) had hypoventilation in the blocked lobe without complete atelectasis. In our opinion, this valve is preferable for the treatment of empyema with BPFs because it was originally developed and tested to treat an infectious process, although not acute, in the bronchial tree, lungs, and pleura.

Most recently, Ding et al. [21] reviewed 34 case reports and 10 case series comprising 208 patients with persistent air leaks of various etiology treated with EBVs. They found that complete resolution of air leaks was obtained within less than $24 \mathrm{~h}$ in the majority of patients (60\%). In the present case series, complete resolution of the leak was not achieved within less than 7 days (7-21) during INPT and/or EBV implantation; however, we did not observe major complications related to EBV implantation and VAC therapy, including bleeding from the lung or mediastinal structures or residual lung parenchymal atelectasis. Moreover, 1 patient with poor condition was weaned from ventilatory support over 51 days after EBV placement and on day 42 after the cessation of air leakage.

Despite the fact that the optimal treatment of empyema with BPF should be individualized, the basis goals of surgery for empyema, since Hippocrates of Kos (460-370 BC), were, are, and should be (1) full pus evacuation/debridement of the pleural cavity and (2) full lung expansion [14].

At the first glance, it is illogical to use a valve that reduces the air flow through the blocked pulmonary lobe, thereby inhibiting its re-expansion (the second goal); on the other hand, our approach is based on the conclusion that INPT, probably with the help of collateral ventilation between lobes/segments, should compensate for the negative impact of the EBV blockage of lung expansion and should ensure complete postoperative evacuation (the first goal).

The combination of these two approaches makes it possible to (1) secure minimal invasive break of the vicious circle where a severe septic process is maintained by re-infection constantly repeated via fistula, in turn making it impossible to close the fistula using invasive methods, and (2) achieve essential lung parenchyma re-expansion and definitive healing without any additional surgical interventions.

The main limitations of our study are its retrospective nature, the small number of patients with varying heterogeneous empyema and treatment modalities, which makes it impossible to match any true control group from our previous experience to compare the treatment results. Therefore, further studies are needed to evaluate the role of EBV and INPT combinations in the management of patients with complex empyema (stage II/III, recurrent/chronic) and large BPF(s) and incomplete re-expansion of residual lung parenchyma. However, these limitations do not reduce the importance and clinical relevance of the proposed treatment modalities, and we believe that first-line options to manage these patients before major surgery, or if any other surgical option has failed, should be various combinations of debridement/decortication through thoracostomy (minimally invasive, VATS or open) with EBV implantation before, within, or after the surgical procedures to resolve/decrease the air leak. Adjunct INPT/VAC therapy should be used to allow full/maximum residual/atelectatic parenchyma expansion and full evacuation. Furthermore, we agree with other authors [9] that these alternative treatments should be discussed as soon as possible because spontaneous closure of the chest wall was achieved in the last 5 patients in the relatively early stages of empyema.

\section{Conclusions}

Thoracostomy with intrathoracic negative pressure therapy, endobronchial valve implantation with tube drainage, and a combination of the two could adequately manage patients with pleural empyema with or without a persistent air leakage fistula.

\section{Conflict of interest}

The authors declare no conflict of interest.

\section{References}

1. Varker KA, Ng T. Management of empyema cavity with the vacuum-assisted closure device. Ann Thorac Surg 2006; 81: 723-5.

2. Scarci M, Abah U, Solli P, et al. EACTS expert consensus statement for surgical management of pleural empyema. Eur J Cardiothorac Surg 2015; 48: 642-53.

3. Shen KR, Bribriesco A, Crabtree T, et al. The American Association for Thoracic Surgery consensus guidelines for the management of empyema. J Thorac Cardiovasc Surg 2017; 153: e129-46.

4. Keshishyan S, Revelo AE, Epelbaum O. Bronchoscopic management of prolonged air leak. J Thorac Dis 2017; 9 (Suppl 10): S1034-46.

5. Levin A, Sklyuev S, Felker I, et al. Endobronchial valve treatment of destructive multidrug-resistant tuberculosis. Int J Tuberc Lung Dis 2016; 20: 1539-45. 
6. Żurek W, Makarewicz W, Bobowicz M, et al. The treatment of chronic pleural empyema with laparoscopic omentoplasty. Initial report. Videosurgery Miniinv 2014; 9: 548-53.

7. Schneiter D, Grodzki T, Lardinois D, et al. Accelerated treatment of postpneumonectomy empyema: a binational long-term study. J Thorac Cardiovasc Surg 2008; 136: 179-85.

8. Palmen M, van Breugel HN, Geskes GG, et al. Open window thoracostomy treatment of empyema is accelerated by vacuum-assisted closure. Ann Thorac Surg 2009; 88: 1131-6.

9. Sziklavari Z, Grosser C, Neu R, et al. Complex pleural empyema can be safely treated with a vacuum-assisted closure. J Cardiothorac Surg 2011; 6: 130.

10. Hofmann HS, Schemm R, Grosser C, et al. Vacuum-assisted closure of pleural empyema without classic open-window thoracostomy. Ann Thorac Surg 2012; 93: 1741-2.

11. Sziklavari Z, Grosser C, Neu R, et al. Minimally invasive vacuum-assisted closure therapy in the management of complex pleural empyema. Interact Cardiovasc Thorac Surg 2013; 17: 49-53.

12. Sziklavari Z, Ried M, Zeman F, et al. Short-term and long-term outcomes of intrathoracic vacuum therapy of empyema in debilitated patients. J Cardiothorac Surg 2016; 11: 148.

13. Groetzner J, Holzer M, Stockhausen D, et al. Intrathoracic application of vacuum wound therapy following thoracic surgery. Thorac Cardiovasc Surg 2009; 57: 417-20.

14. Molnar TF. Current surgical treatment of thoracic empyema in adults. Eur J Cardiothorac Surg 2007; 32: 422-30.

15. Gkegkes ID, Mourtarakos S, Gakidis I. Endobronchial valves in treatment of persistent air leaks: a systematic review of clinical evidence. Med Sci Monit 2015; 21: 432-8.

16. Snell GL, Holsworth L, Fowler S, et al. Occlusion of a broncho-cutaneous fistula with endobronchial one-way valves. Ann Thorac Surg 2005; 80: 1930-2.

17. Schweigert M, Kraus D, Ficker JH, Stein HJ. Closure of persisting air leaks in patients with severe pleural empyema - use of endoscopic one-way endobronchial valve. Eur J Cardiothorac Surg 2011; 39: 401-3.

18. Gudbjartsson T, Helgadottir S, Eku L. One-way endobronchial valve for bronchopleural fistula after necrotizing pneumonia. Asian Cardiovasc Thorac Ann 2013; 21: 498-9.

19. Mahajan AK, Verhoef P, Patel SB, et al. Intrabronchial valves: A case series describing a minimally invasive approach to bronchopleural fistulas in medical intensive care unit patients. J Bronchology Interv Pulmonol 2012; 19: 137-41.

20. Kalatoudis H, Nikhil M, Zeid F, Shweihat Y. Bronchopleural fistula resolution with endobronchial valve placement and liberation from mechanical ventilation in acute respiratory distress syndrome: a case series. Case Rep Crit Care 2017; 2017: 3092457.

21. Ding M, Gao Y, Zeng XT, et al. Endobronchial one-way valves for treatment of persistent air leaks: a systematic review. Respir Res 2017; 18: 186.

Received: 1.11.2019, accepted: 20.01.2020 